\title{
Poliomyelitis: a new old disease. What is the value of continuing education programs for health professionals?
}

\author{
Poliomielite: uma nova velha doença. Qual o valor dos programas de educação continuada \\ para profissionais da saúde?
}

\section{Dear Editor,}

We read with great interest the paper by Laurenti et al. ${ }^{1}$ that performed a paper about International Classification of Diseases and post-poliomyelitis syndrome. Poliomyelitis is an acute infectious disease which is caused by the poliovirus. The poliovirus is directly transmitted from person to person, whenever they are in contact with infected mucus and/or phlegm from the nose or mouth, or in direct contact with infected feces. Approximately $90 \%$ of the individuals infected do not present any symptoms. However, the affected ones can show a variety of symptoms, after the virus enters the bloodstream $^{1}$. In approximately $2 \%$ of the cases, the virus reaches the central nervous system, where it preferably infects and destroys motor neurons. This normally results in muscular weakness and acute flaccid paralysis ${ }^{1}$. After the introduction of an effective vaccination program more than 50 years ago - the number of new cases dramatically dropped. The wild-type poliovirus was eliminated from the western hemisphere, and the number of cases continually decreases in other parts of the world. Nevertheless, new cases of poliomyelitis have been reported in certain African, Asian, and Middle East countries ${ }^{2}$. For instance new cases of poliomyelitis were registered in Syria, that had not registered any case of poliomyelitis since $1995^{2}$; this new register was primarily attributed to the civil war that prevented children to be vaccinated ${ }^{3}$. Since polio is still a threat in those aforementioned regions, healthcare professionals should be aware of the clinical characteristics of the disease.

In addition, a significant number of patients with history of poliomyelitis report a late-onset of neuromuscular symptoms, followed by decline in their functional capacity. These symptoms are normally referred to as post-poliomyelitis syndrome (PPS) ${ }^{4}$. PPS is characterized by a new increased muscle weakness, fatigue, muscle and joint pain, muscle cramps, cold intolerance, and severe lung problems ${ }^{4}$.

Recently, we conducted a study that evaluated the knowledge about poliomyelitis and PPS among Brazilian physical education professionals ${ }^{5}$. The knowledge about poliomyelitis and PPS were found to be low among these professionals, especially among those who had not access to previous information about PPS ${ }^{5}$. This situation could compromise the service provided, the services provided by these professionals. Moreover, it is possible that similar levels of knowledge about poliomyelitis and PPS may be present among other health professionals, including nurses, physiotherapists, physicians, and nutritionists. Hence, studies should be conducted to better understand the knowledge of health on poliomyelitis and PPS, as well as public training policies should be implemented to increase knowledge about poliomyelitis and PPS in order to improve the services provided to the patients. Overall, we would like to express our congratulations to Laurenti et al. ${ }^{1}$ on their interesting paper.

Claudio Andre Barbosa de Lira ${ }^{1}$, Marília dos Santos Andrade $^{2}$, Rodrigo Luiz Vancini ${ }^{3}$

\section{Acknowledgment}

We would like to thank Fundação de Amparo à Pesquisa do Estado de Goiás (FAPEG, Brazil; grant no. 2009/10267000347) that supported our studies about poliomyelitis and post-poliomyelitis syndrome.

\footnotetext{
${ }^{1}$ Setor de Fisiologia Humana e do Exercício, Faculdade de Educação Fisica, Universidade Federal de Goiás, Goiânia Go, Brazil;

${ }^{2}$ Departamento de Fisiologia, Universidade Federal de São Paulo, Sao Paulo SP, Brazil;

${ }^{3}$ Centro de Educação Física e Desportos, Universidade Federal do Espírito Santo, Vitória ES, Brazil.

Correspondence: Claudio Andre Barbosa de Lira; Faculdade de Educação Física, Campus Samambaia, Universidade Federal de Goiás; Caixa Postal 131; 74001-970 Goiânia GO, Brasil; E-mail: andre.claudio@gmail.com

Conflict of interest: There is no conflict of interest to declare.

Received 19 December 2013; Received in final form 28 April 2014; Accepted 16 May 2014.
} 
1. Laurenti R, Nubila HB, Quadros AA, Conde MT, Oliveira AS. The International Classification of Diseases, the family of international classifications, the ICD-11, and post-polio syndrome. Arq Neuropsiquiatr 2013;71:3-10.

2. World Health Organization. Poliomyelitis. Fact sheet 114. Available from: http://www.who.int/mediacentre/factsheets/fs114/en/. (accessed Nov 22, 2013).

3. WHO. Third dose of polio vaccine. Reported estimates of Pol3 coverage. http://apps.who.int/immunization_monitoring/ globalsummary/timeseries/tscoveragepol3.html. (accessed Dec 04, 2013)

4. Trojan DA, Cashman NR. Post-poliomyelitis syndrome. Muscle Nerve 2005;31:6-19.

5. de Lira CAB, Alves TMA, Peixinho-Pena LF, et al. Knowledge among physical education professionals about poliomyelitis and post-poliomyelitis syndrome: a cross-sectional study in Brazil. Degenerative Neurological and Neuromuscular Disease 2013;3:41-46. 